Running title: Parasite effects on stickleback

\title{
The association of feeding behavior with the resistance and tolerance to parasites in recently diverged sticklebacks
}

\author{
Jaime M. Anaya-Rojas*,1,2,3, Franziska S. Brunner ${ }^{4}$, Nina Sommer ${ }^{1}$, Ole Seehausen ${ }^{2,3}$, \\ Christophe Eizaguirre ${ }^{4}$, and Blake Matthews ${ }^{1}$
}

1. Eawag, Aquatic Ecology Department, Center of Ecology, Evolution and Biogeochemistry, Kastanienbaum, Switzerland.

2. Eawag, Department of Fish Ecology and Evolution, Center of Ecology, Evolution and Biogeochemistry, Kastanienbaum, Switzerland.

3. Division of Aquatic Ecology and Macroevolution, Institute of Ecology and Evolution, University of Bern, Bern, Switzerland.

4. Queen Mary University of London, School of Biological and Chemical Sciences, Fogg Building, Mile End Road, London E1 4NS, United Kingdom.

\section{*Correspondence author:}

Jaime M. Anaya-Rojas

e-mail: jaime.anaya-rojas@eawag.ch

Phone: (+41) 58765 2173, Fax: (+41) 587652168

Statement of authorship: JMAR analyzed the data and wrote the first draft of the manuscript. JMAR and FSB performed the experiment, and NS contributed to data collection and writing the manuscript. BM and CE conceived the experiment and contributed substantially to the revisions of the manuscript. OS made substantial contributions to the structure and revisions of the manuscript draft. Here, we confirm that we do not have any conflict of interest.

This article has been accepted for publication and undergone full peer review but has not been through the copyediting, typesetting, pagination and proofreading process, which may lead to differences between this version and the Version of Record. Please cite this article as doi:

$10.1111 /$ jeb. 12934

This article is protected by copyright. All rights reserved. 


\begin{abstract}
Divergent natural selection regimes can contribute to adaptive population divergence, but can be sensitive to human-mediated environmental change. Nutrient loading of aquatic ecosystems, for example, might modify selection pressures by altering the abundance and distribution of resources and the prevalence and infectivity of parasites. Here, we used a mesocosm experiment to test for interactive effects of nutrient loading and parasitism on host condition and feeding ecology. Specifically, we investigated whether the common fish parasite Gyrodactylus sp. differentially affected recently diverged lake and stream ecotypes of three-spined stickleback (Gasterosteus aculeatus). We found that the stream ecotype had a higher resistance to Gyrodactylus sp. infections than the lake ecotype, and that both ecotypes experienced a cost of parasitism, indicated by negative relationships between parasite load and both stomach fullness and body condition. Overall, our results suggest that in the early stages of adaptive population divergence of hosts, parasites can affect host resistance, body condition, and diet.
\end{abstract}

Keywords: three-spined stickleback, diet, parasites, environmental change, eutrophication, aquatic ecosystems, metabolic condition, trade-offs, adaptive divergence

This article is protected by copyright. All rights reserved. 


\section{Introduction}

Contrasting environmental conditions can generate the divergent selection pressures that drive adaptive population divergence (Schluter, 2000; Nosil, 2012), and during this process several traits linked to species interactions can evolve rapidly, including those associated with feeding behaviours and defences against predators and parasites (Kortet et al., 2010; Eizaguirre \& Lenz, 2010; Karvonen \& Seehausen, 2012; Schluter, 2000). The evolution of such traits might influence the buildup of reproductive isolation (Servedio et al., 2011; Nosil, 2012; Eizaguirre et al., 2009a), particularly if they are also involved in mate choice (Maan \& Seehausen, 2011) and local adaptation (Eizaguirre \& Lenz, 2010; Eizaguirre et al., 2011; Konijnendijk et al., 2013; Bassar et al., 2010; Arnegard et al., 2014). During the early stages of adaptive population divergence, environmental change can weaken divergent selection regimes, and this might erode ecological and genetic differentiation between populations (Hendry et al., 2009; Seehausen et al., 2014; Vonlanthen et al., 2012). In most cases, however, we lack a mechanistic understanding of how environmental change, be it abiotic or biotic, can influence performance variation among and within diverging populations. This makes it difficult to predict the effect of environmental change on the dynamics of population divergence (Nosil, 2012; MacColl, 2011).

The resistance and tolerance of hosts to parasites are traits that can both evolve rapidly (Råberg, 2014; Siva-Jothy \& Thompson, 2002; Murray et al., 1998) and influence host energy acquisition and resource assimilation over a range of environmental conditions (Pianka, 1981; Huey et al., 2001; Howick \& Lazzaro, 2014). Resistance is the ability of individuals to limit their parasite load, and is measured as the number of parasites acquired per individual host over a given time period (Råberg et al., 2009). Tolerance, on the other hand, is the ability of individuals to reduce the harmful effects of a given parasite load, and can be estimated (at the population level) as the slope of the relationship between parasite load and proxies of fitness (Schneider \& Ayres, 2008; Råberg et al., 2009; Kaufmann et al., 2014). The evolution of host resistance and tolerance strongly depends on how parasites affect trade-offs between immune defense and life history traits (Poulin, 2007; Råberg, 2014; Hamilton \& Zuk, 1989). For instance, when hosts lack the genetic material to fight off infections, they may increase energy acquisition to compensate for the costs of parasitism (Howick \& Lazzaro, 2014; Ponton et al., 2011; Zuk \& Stoehr, 2002). If individual hosts

This article is protected by copyright. All rights reserved. 
are in positive energy balance (e.g. full guts, ample fat reserves), they might be able to either better cope with the physiological demands of the infection or to mount a more effective immune response (Zuk \& Stoehr, 2002). In general, host responses to parasites tend to be strongly dependent on environmental conditions that determine host energy balance (Wong \& Candolin, 2015; Budria \& Candolin, 2014).

In aquatic systems, nutrient loading can have strong effects on host-parasite interactions (Johnson et al., 2008, 2007; Budria \& Candolin, 2014), by changing the chemical (e.g. phosphorus and oxygen levels), physical (e.g. light, turbidity) and biological properties of aquatic ecosystems (Smith \& Schindler, 2009). Nutrient loading has been shown to alter resource availability and competitive interactions (Leach et al., 1977; Talbot \& Hole, 1994), predation risk (Cothran et al., 2012; Van de Meutter et al., 2005), mating behaviour (Cothran et al., 2012; Jaervenpaeae \& Lindstroem, 2004), and the prevalence and virulence of parasites (Zuk \& Stoehr, 2002; Kortet et al., 2010; Johnson et al., 2012; Domenici et al., 2007; Halstead et al., 2014). Previous experiments in aquatic systems have found strong effects of nutrient loading on the morphology and behaviour of vertebrates (Johnson et al., 2010; Budria \& Candolin, 2014). However, less is known about how nutrient loading might affect parasite resistance, tolerance, and feeding ecology of hosts in the early stages of adaptive divergence.

The stickleback-Gyrodactylus model system is useful for investigating the interactive effects of parasitism and environmental change (i.e. nutrient loading) on the evolution of host resistance during adaptive population divergence. Lake and stream three-spined stickleback (hereafter, sticklebacks) populations that are genetically and phenotypically differentiated (i.e. ecotypes) have evolved multiple times in the Northern hemisphere since the last glaciation $(\simeq 12$ 000 years) (Hendry et al., 2009; Feulner et al., 2015). For our study, we chose a pair from the Lake Constance region in central Europe that has diverged very recently ( $<150$ years) (Lucek et al., 2010), concomitant with dramatic changes in nutrient levels in Lake Constance. Lake Constance has experienced a prolonged phase of eutrophication (1950-1980: total Phosphorus, TP increased from $\simeq 10$ to $80 \mu \mathrm{g} / L)$ and re-oligotrophication $(1980-2010$ : TP decreased from $\simeq 80$ to $10 \mu \mathrm{g} / \mathrm{L}$ ) (Jochimsen et al., 2013), but the ecological and evolutionary effects of these nutrient dynamics on the resident stickleback populations are unknown. The specific lake-stream pair that we used is phenotypically divergent in body size, growth rate (Lucek et al., 2012), and

This article is protected by copyright. All rights reserved. 
morphology (Berner et al., 2011; Lucek et al., 2013), and is genetically differentiated at several putatively adaptive loci (Marques et al., 2016). For a parasite, we chose the monogean (Platyhelminthes) flatworm, Gyrodactylus spp. (hereafter, Gyrodactylus), because it is a common ectoparasite of sticklebacks and other fish (Bakke et al., 2007; Rahn et al., 2015; Kalbe et al., 2002; Raeymaekers et al., 2011; Stephenson et al., 2015), and it is known to drive local adaptation in other stickleback populations (Eizaguirre \& Lenz, 2010; Konijnendijk et al., 2013). Gyrodactylus is a flatworm that reproduces on the skin and gills of fish (Bakke et al., 2007), and can increase host mortality (Bakke et al., 2007), reduce body condition (Eizaguirre et al., 2011), and reduce life-time reproductive success (Eizaguirre et al., 2009b). It has no intermediate host, and it is generally more common in stream than in lake environments (Bakke et al., 2007; Eizaguirre et al., 2011; Kalbe et al., 2002).

We performed a 7-week mesocosm experiment to investigate how closely related lake and stream ecotypes of stickleback differ in their resistance and tolerance to the monogenean ectoparasite Gyrodactylus in aquatic ecosystems with low and high levels of nutrient loading. In this study, we tested the following two predictions. First, we predicted that lake and stream ecotypes would differ in their resistance and tolerance to Gyrodactylus infections. This prediction is based on previous work showing rapid parasite-mediated evolution of stickleback immune systems in other populations (Eizaguirre et al., 2012a,b). Second, we predicted that nutrient loading might differentially affect the resistance and tolerance of both ecotypes to parasite exposure, partly because of the potential impacts of nutrient loading on the energy balance (e.g. stomach fullness), diet composition (i.e. gut contents), and body condition (a fitness proxy) of sticklebacks (Schlotz et al., 2013; Budria \& Candolin, 2014; Howick \& Lazzaro, 2014).

\section{Materials and methods}

\section{Mesocosms Experiment}

Our experimental setup consisted of 40 outdoor mesocosms, and was a complete randomized block design, with factorial combinations of fish ecotype (lake and stream), nutrient level (high and low nutrients, HN and LN), and Gyrodactylus exposure (exposed and unexposed, G+ and G-,

This article is protected by copyright. All rights reserved. 
Fig. 1). The experiment lasted 7 weeks, from May 3 to June 21, 2013. Each mesocosm was filled with $1000 \mathrm{~L}$ of filtered water from Lake Lucerne (Switzerland) and seeded with a mixture of sand, gravel, benthic substrate, and zooplankton. We amended nutrient levels by adding 20 $m l$ of $\mathrm{NaNO}_{3}$ and $\mathrm{HNa}_{2} \mathrm{PO}_{4}$ stock solution to achieve the following target concentrations: $640 \mu \mathrm{g}$ $N / L$ and $40 \mu \mathrm{g} P / L$ in $\mathrm{HN}$ tanks, and $80 \mu \mathrm{g} \mathrm{N} / L$ and $5 \mu \mathrm{g} P / L$ in $\mathrm{LN}$ tanks, which represents approximately the median and the minimum, respectively, of the total phosphorus concentration in Lake Constance over the past 50 years (Jochimsen et al., 2013). Each mesocosm received either 6 or 7 stickleback so as to standardize biomass among mesocosms (Mean-lake $=24.55 \mathrm{~g}$ $\pm 0.621 S E$, Mean-stream $=23.15 \mathrm{~g} \pm 0.292 S E)$

\section{Fish Collection and Parasite Exposure}

We collected stream sticklebacks from two streams (Aubach: $47^{\circ} 19^{\prime} 37.45^{\prime \prime} \mathrm{N} 9^{\circ} 34^{\prime} 12.82^{\prime \prime} \mathrm{E}$; and Zapfenbachkrummensee Kanal: $\left.47^{\circ} 21^{\prime} 20.65^{\prime \prime} \mathrm{N} 9^{\circ} 36^{\prime} 11.94^{\prime \prime} \mathrm{E}\right)$ and lake sticklebacks from the shore of an inlet delta of Lake Constance (Staad: $47^{\circ} 29^{\prime} 8.30^{\prime \prime} \mathrm{N} 9^{\circ} 32^{\prime} 38.25^{\prime \prime} \mathrm{E}$ ) in early spring 2013. Twenty lake and stream sticklebacks were dissected to estimate the abundance of Gyrodactylus parasites in these natural populations. For the experiment, we initially removed Gyrodactylus by treating wild-caught fish with a 1:4000 diluted solution of formalin (Raeymaekers et al., 2011; Buchmann \& Kristensson, 2003). A visual inspection of all fish under stereomicroscope revealed no living parasites after disinfection. After one week, we then performed a standardized infection of the fish that we used for the mesocosm experiment. Fish were anesthetized $(N=278)$ with $0.1 \%$ MS222 (Gilderhus \& Marking, 1987) and placed on a petri dish filled with saline solution $(6.4 \mathrm{~g} / \mathrm{L} \mathrm{NaCl})$. With a fine brush, we manually added exactly four individual parasites onto each individual that was part of the infection treatment $\left(G_{+}\right)$. We used two parasites that originated from either naturally infected lake fish or stream fish, so as to account for possible differences in hostparasite coevolution (Eizaguirre et al., 2011; Konijnendijk et al., 2013). Unexposed fish (G-) used in the experiment were handled in the same way but received no parasites. After this procedure, the fish were kept in $5 L$ aquaria for a week prior to their introduction into the mesocosms.

This article is protected by copyright. All rights reserved. 


\section{Parasite levels, fish condition and diet}

At the end of the experiment, we caught the surviving fish $(N=199$ fish out of $N=278)$, euthanized them using an overdose of MS222, and counted the number of Gyrodactylus per fish (i.e. parasite load). Three tanks were excluded from the experiment because of low survival (see Fig-S1 and Table-S3). Additionally, one randomly chosen fish from each mesocosm was excluded from all analyses $(N=40)$, because it was needed for another experiment (Brunner et al submitted). For the remaining 159 fish used in the current study, we measured standard length ( $\mathrm{mm}$, $\pm 1 \mathrm{~mm})$, body weight $(\mathrm{g}, \pm 0.01 \mathrm{~g})$, liver weight $(\mathrm{mg}, \pm 0.001 \mathrm{mg})$, and wet gut mass $(\mathrm{mg}, \pm$ $0.001 \mathrm{mg}$ ) (see Table-S3 for descriptive statistics). Fish guts were stored in saline solution (6.4 $g / L \mathrm{NaCl})$ and frozen at $-20^{\circ} \mathrm{C}$ in separate vials for later dietary analyses.

The hepatosomatic index ( $\mathrm{HSI})$, was used as a proxy of individual variation in body condition, where $H S I=\left[L M /\left(B M-W_{F S}\right)\right] x 100$, and $L M$ is the wet liver mass $(g)$ and $B M$ wet body mass $(g)$ (Chellappa et al., 1995; Hammerschmidt \& Kurtz, 2005; Kurtz et al., 2004). We estimated energy balance based on the relative fullness index of the fish guts (FI), where $F I=$ $\left[W_{S C} / B M\right] x 100$, and $W_{S C}$ is the difference between the mass of the full stomach and empty stomach (Magnusson et al., 2003). To quantify diet composition, the whole content of each gut was flushed into petri dishes and the prey items were identified to the lowest taxonomic level possible (Streble \& Krauter, 2006; Tachet et al., 2000). Individual prey were counted on a $2.5 \times 2.5$ $m m$ grid under a stereomicroscope, and in our analyses we focused on the six most abundant prey items, namely Collembola, Nymphs, Chironomidae, Ostracoda, Chydoridae, and Cyclopoida (Table-S1).

\section{Statistical Analyses}

The effects on fish mortality were tested using generalized linear mixed effect models (GLMM), with a binomial family (logit-link); fish ecotype, nutrient levels, parasite exposure and their interactions were fixed effects and block was used as random effect. To analyse variation in parasite load (number of Gyrodactylus per fish), we used a GLMM with the number of parasites as the response variable, body length as an offset, a negative binomial error family (square-root link), and tanks nested within blocks as random effects. Parameters were estimated by Penalized Quasi Maximum

This article is protected by copyright. All rights reserved. 
Likelihood (PQL) with the $R$ package MASS, which produces a better dispersion of the fitted and predicted values compared to other $R$ packages (e.g., Ime4 and gImmADMB, Zuur et al., 2009; Bolker et al., 2009).

We tested for the effects of our treatments on body condition (HSI) and the fullness index (FI) with linear mixed effect models (LMM) with tank nested within block as random effects and parasite load as a continuous variable. To test if nutrient loading altered the resistance and tolerance of the ecotypes to Gyrodactylus, we performed mixed effects ANCOVA with either body condition $(\mathrm{HSI})$ or diet $(\mathrm{FI})$ as responses variables, with the interaction of ecotype $x$ nutrient $x$ parasite load as explanatory variables (Råberg et al., 2009), and with tanks nested within block as a random effect. Differences between slopes were tested using likelihood ratio tests and the $X^{2}$ test statistic following (Hayward et al., 2014). To test if slopes were significantly different from 0 (i.e. tolerant or intolerant) we used a $t$ - test with the $R$ package Imertest.

To analyse variation in diet composition, we focused on changes in diet community composition among treatments within experimental blocks. To this end, we used a distance-based redundancy analysis (db-RDA) framework with the function capscale () in the $R$-package vegan in which we: (i) Hellinger transformed the abundance diet matrix by block (Borcard et al., 2011), (ii) averaged the Hellinger transformed matrix by tank and used it as our response matrix in the $\mathrm{db}-\mathrm{RDA}$, and (iii) tested for the significance (RDA's $F$ statistic) of our experimental treatments on the transformed matrix by permuting all treatments within a block 999 times. We also tested for the effects of the experimental treatments on each individual prey item from the Hellingertransformed species matrix (159 × 6 matrix) in a binomial GLMM model, with tank nested within block as a random effect (Table-S3). For all LMM and GLMM, we estimated $X^{2}$ and P-values in an anova Type II analysis with the function Anova () from the car $R$-package. All statistical analyses were performed in $R$-version 3.2.3 (R Core Team, 2015) and the data is available online on Dryad http://dx.doi.org/10.5061/dryad.b0846.

\section{Results}

In this experiment, 79 out of 278 fish died during the seven weeks of the experiment. Overall, lake sticklebacks died more than stream sticklebacks (Ecotype: $X^{2}=4.164, \mathrm{P}=0.041$, Fig-S1), and

This article is protected by copyright. All rights reserved. 
mortality was highest for lake sticklebacks that were exposed to Gyrodactylus (G+) (Ecotype by Exposure interaction: $X^{2}=6.912, \mathrm{P}=0.008$, Fig-S1). We did not find a significant main effect of nutrients (Nutrients: $X^{2}=0.033, \mathrm{P}=0.854$ ) on mortality.

Prediction 1 (ecotype differences in host resistance and tolerance)-We found that parasite load was highest for lake fish, both in the wild (Lake-wild=30.4 $\pm 5.23 \mathrm{SE}$, Stream-wild=4.68 \pm 1.75 $\mathrm{SE}, X_{1,40}^{2}=30.22, \mathrm{P}<0.001$ ) and in the experiment (Lake-experiment $=36.27 \pm 13.33 \mathrm{SE}$, Streamexperiment $=3.01 \pm 5.65 \mathrm{SE} ; X_{1,159}^{2}=20.262, \mathrm{P}<0.001$, Fig. $2 \mathrm{~A}$ ). In the experiment, parasite load was negatively related to the body condition $\left(X_{1,159}^{2}=12.136 \mathrm{P}<0.001\right)$, and there was no effect of ecotype on the slope of this relationship (Table-S2), implying that both ecotypes were equally intolerant to parasite load (Fig. 3A). We also found that stomach fullness (FI) was negatively related to parasite load $\left(X_{1,159}^{2}=4.838, \mathrm{P}=0.028\right)$ and that there was no effect of ecotype on the slope of this relationship (Table-S2). However, when we split this analysis by ecotype, we found that the relationship between parasite load and gut fullness was significantly negative for lake fish $\left(X_{1,72}^{2}=6.197, \mathrm{P}<0.05\right)$ but not for stream fish $\left(X_{1,87}^{2}=0.264, \mathrm{P}>0.1\right.$, Figure 3D).

Prediction 2 (interactive effects of nutrient)- Overall, fish of both ecotypes were in better condition in $\mathrm{HN}$ tanks $\left(X_{1,159}^{2}=7.406, \mathrm{P}<0.01\right.$, Fig. 2B, Table 1$)$. While we found no effects of nutrients on the parasite load of stream fish (Stream-HN=2.7 $\pm 0.777 \mathrm{SE}$, Stream-LN=3.28 $\pm 0.919 \mathrm{SE}$, $X_{1,87}^{2}=0.011, \mathrm{P}=0.916$ ), the parasite load of lake stickleback was lower in $\mathrm{HN}$ compared to $\mathrm{LN}$ tanks (Lake-HN=29.60 $\pm 18.9 \mathrm{SE}$, Lake-LN= 43.74 $\left.\pm 18.94 \mathrm{SE}, X_{1,72}^{2}=7.47, \mathrm{P}<0.01\right)$. In addition, we found that the lake fish in the LN tanks had higher parasite loads and there were significant negative relationships between parasite load and body condition (Lake-HN: slope $=-0.027 \pm 0.024$ SE, t-test $60.23=-1.158, P=0.251$; Lake-LN: slope $=-0.063 \pm 0.021 S E$, t-test $61.03=-2.942, P<0.01$, Fig. 3B) and stomach fullness (Lake-HN: slope $=-0.051 \pm 0.039 \mathrm{SE}$, t-test ${ }_{58.71}=-1.198, P=0.199$; Lake-LN: slope $=-0.084 \pm 0.036 \mathrm{SE}$, t-test $63.21=-2.307, \mathrm{P}=0.024$, see Fig. $3 \mathrm{E})$.

Ecotypes did not differ in their relative gut fullness (Table 1 and Fig. 2C) or in their diet composition (Table 2, Fig. 4). However, initial parasite exposure significantly altered diet composition (F= 2.776, $\mathrm{P}<0.05$; Table 2 and Fig. 4), such that parasite-exposed fish ate more copepods $\left(X_{1,159}^{2}=\right.$ 4.152, $\mathrm{P}=0.042)$ and fewer nymphs $\left(X_{1,159}^{2}=4.703, \mathrm{P}=0.03\right)$ than non-exposed fish (see Fig-S2 and Table-S1 and S3).

This article is protected by copyright. All rights reserved. 


\section{Discussion}

Understanding how environmental changes affect species evolution is an ongoing challenge. Here we predicted that lake and stream stickleback ecotypes would differ in their resistance and tolerance to Gyrodactylus and that nutrient loading would differentially affect the host-parasite interactions for each ecotype. Overall, our results provide partial support for both predictions. First, we found that lake sticklebacks had higher mortality and lower resistance to infection than stream sticklebacks when exposed to Gyrodactylus (Fig. 2). However, among the surviving fish, both lake and stream ecotypes were equally intolerant to parasite load (i.e. similar slopes in Fig. 3A). Second, we found that nutrient loading increased the resistance of lake but not stream stickleback, and, exclusively for lake stickleback, we found some evidence that nutrient loading reduced the cost of parasite load (Fig. 3B).

In the wild, lake and stream stickleback ecotypes inhabit different foraging habitats during most of their life cycle, which expose them to contrasting parasite communities (Kalbe et al., 2002; Karvonen et al., 2015; Feulner et al., 2015). Around the Lake Constance basin, stream sticklebacks reside year round in streams, feed primarily on benthic prey items, and are exposed to a lower diversity of parasites than lake fish (Lucek et al., 2013; Moser et al., 2012, 2015b; Karvonen et al., 2015). Lake sticklebacks, on the other hand, live most of their life in the open water of the lake and migrate to nearshore environments and stream channels to breed (Lucek et al., 2013; Moser et al., 2012). They primarily feed on planktonic prey and are exposed to a higher diversity of parasites than stream fish (Moser et al., 2012; Karvonen et al., 2015; Moser et al., 2015b; Lucek et al., 2013). Previous work on other stickleback populations has shown that contrasting foraging habitats and parasite communities are important drivers of phenotypic and genetic differentiation (Feulner et al., 2015; Karvonen et al., 2015), and that rapid evolution of host resistance might be common during the formation of ecotypes (Eizaguirre et al., 2012b,a, 2009a, 2011; Stutz et al., 2014; Oke et al., 2016; Feulner et al., 2015).

Rapid evolution of resistance to contrasting parasite communities is a common outcome of host-parasite interactions (Schmid-Hempel, 2011). The higher level of resistance of stream stickleback could result from coevolution of stream fish with Gyrodactylus, one of the most common parasites in stream environments (Kalbe et al., 2002; Eizaguirre et al., 2011). In other stickleback

This article is protected by copyright. All rights reserved. 
populations, adaptation to contrasting parasite communities in lakes and streams have resulted in divergent immune responses between ecotypes (Eizaguirre \& Lenz, 2010; Feulner et al., 2015; Karvonen \& Seehausen, 2012). Mainly because contrasting parasite communities are strongly associated with differences in the frequency of alleles of the major histocompatibility complex (MHC) between populations (Eizaguirre et al., 2012a, 2009a; Matthews et al., 2010). Therefore, if host-parasite coevolutionary dynamics in Lake Constance are similar to other systems around Europe, it is possible that resistance alleles, of either the MHC or other relevant genes, have recently increased in frequency in the stream but not in the lake populations (Eizaguirre \& Lenz, 2010; Eizaguirre et al., 2012b,a, 2011). While there is recent evidence for adaptive genomic differentiation between the lake and stream ecotypes from in Lake Constance (Karvonen et al., 2015; Moser et al., 2012, 2015a; Roesti et al., 2015; Lucek et al., 2013; Marques et al., 2016), nothing is known about differentiation of MHC genes for this lake-stream pair and this should be addressed in further studies.

While the evolution of host resistance can influence diversification and maintenance of genetic diversity between and within populations (Buckling \& Rainey, 2002; Summers et al., 2003; Eizaguirre et al., 2009b), the evolution of tolerance may favour the spread of parasites (Best et al., 2008; Kaufmann et al., 2014), break down Red-Queen dynamics, and generate multiple stablestates (Best et al., 2014; Råberg, 2014). This is because tolerance can mitigate the negative effects of parasitism, but does not contribute to decreasing parasite load (Best et al., 2014; Råberg, 2014). In our experiment, we did not find significant differences in the degree of tolerance between ecotypes (e.g. slopes in Fig $3 \mathrm{~A}$ are not different). However, we did find lower parasite loads in the lake ecotype at high nutrient levels (Table 1 and S1), and this suggests that lake fish might be able to mitigate the negative effects of parasite load on body condition if they can increase energy intake in more productive environments (Fig 2B-D and 3E). Such compensatory effects could have significant impacts on host-parasite dynamics if they help maintain susceptible host genotypes in the population (Brunner \& Eizaguirre, 2016) or if they allow virulent parasite strains to increase in frequency (Kause \& Ødegård, 2012; Best et al., 2014; Råberg, 2014).

Our experiment also revealed a number of links between individual variation in parasite load, body condition, and diet (i.e stomach fullness and composition). First, the positive relationship between body condition ( $\mathrm{HSI}$ ) and stomach fullness $(\mathrm{FI})$ is consistent with an expected positive re-

This article is protected by copyright. All rights reserved. 
lationship between food acquisition and overall metabolic state. Second, the negative relationship between stomach fullness and parasite number in the lake ecotype suggests potentially higher costs of parasitism for lake fish. This is also consistent with the higher mortality of lake fish when exposed to parasites. In high nutrient environments, lake fish might be able to improve their capacity to cope with Gyrodactylus by increasing feeding rates, or changing their diet (e.g. Fig 3E) so as to include more profitable prey (Huey et al., 2001; Arrington et al., 2002; Pianka, 1981). Second, despite known ecotype differences in feeding traits (Lucek et al., 2013; Berner et al., 2011; Marques et al., 2016), in a common foraging environment we found no diet differentiation between ecotypes, but found that stickleback exposed to Gyrodactylus ate more cyclopoids and fewer nymphs than non-exposed individuals (Fig. 4, Fig-S1 and Table-S2).

More work on the food quality of different prey items and the effect of these parasites on the functional response of sticklebacks would be necessary to determine if the diet changes associated with parasite exposure were indicative of a compensatory mechanism or not. While it is well known that trophically transmitted parasites can affect host feeding behaviour (e.g. Schistocephalus and Diplostomum parasites on stickleback feeding rate Lefèvre et al., 2009; Aeschlimann et al., 2000; Jakobsen et al., 1988; Milinski, 1993), our results suggest that directly transmitted parasites can also affect feeding behaviour (e.g. diet preference) and activity (e.g. gut fullness) of their hosts, possibly via effects on host condition.

The stickleback populations used in this experiment were introduced in the Lake Constance region approximately 150 years ago (Lucek et al., 2010; Marques et al., 2016), and over this short time period ( $<100$ generations) they have evolved divergent life history traits such as growth rate, lifespan, and time of first reproduction (Lucek et al., 2013, 2012; Moser et al., 2012). Building on these previous studies, we found that parasitism can influence both ecological interactions between stickleback and their prey (e.g effects of parasite exposure on diet and stomach fullness) and potentially influence selection gradients experienced by hosts (i.e. relationships between parasite load and body condition). However, more work is needed to understand the mechanisms by which parasitism can affect trade-offs between immunity and feeding behaviour, particularly in natural populations.

This article is protected by copyright. All rights reserved. 


\section{References}

Aeschlimann, P., Haeberli, M. \& Milinski, M. 2000. Threat-sensitive feeding strategy of immature sticklebacks (Gasterosteus aculeatus) in response to recent experimental infection with the cestode Schistocephalus solidus. Behav. Ecol. Sociobiol. 49: 1-7.

Arnegard, M.E., McGee, M.D., Matthews, B., Marchinko, K.B., Conte, G.L., Kabir, S., Bedford, N., Bergek, S., Chan, Y.F., Jones, F.C., Kingsley, D.M., Peichel, C.L. \& Schluter, D. 2014. Genetics of ecological divergence during speciation. Nature 511: 307-311.

Arrington, D.A., Winemiller, K.O., Loftus, W.F. \& Akin, S. 2002. How often do fishes "run on empty"? Ecology 83: 2145-2151.

Bakke, T.A., Cable, J. \& Harris, P.D. 2007. The biology of gyrodactylid monogeneans: the "russiandoll killers". Adv. Parasitol. 64: 161-376.

Bassar, R.D., Marshall, M.C., Lopez-Sepulcre, A., Zandona, E., Auer, S.K., Travis, J., Pringle, C.M., Flecker, A.S., Thomas, S.A., Fraser, D.F. \& Reznick, D.N. 2010. Local adaptation in trinidadian guppies alters ecosystem processes. Proc. Natl. Acad. Sci. U.S.A. 107: 3616-3621.

Berner, D., Kauffer, R., Grandchamp, A.C., Raeymaekers, J.A.M., Raesaenen, K. \& Hendry, A.P. 2011. Quantitative genetic inheritance of morphological divergence in a lake-stream stickleback ecotype pair: implications for reproductive isolation. J. Evol. Biol. 24: 1975-1983.

Best, A., White, A. \& Boots, M. 2008. Maintenance of host variation in tolerance to pathogens and parasites. Proc. Natl. Acad. Sci. U.S.A. 105: 20786-20791.

Best, A., White, A. \& Boots, M. 2014. The coevolutionary implications of host tolerance. Evolution 68: $1426-1435$.

Bolker, B.M., Brooks, M.E., Clark, C.J., Geange, S.W., Poulsen, J.R., Stevens, M.H.H. \& White, J.S.S. 2009. Generalized linear mixed models: a practical guide for ecology and evolution. Trends Ecol. Evol. 24: 127-135.

Borcard, D., Gillet, F. \& Legendre, P. 2011. Numerical ecology with R. Springer Science and Business Media.

This article is protected by copyright. All rights reserved. 
Brunner, F.S. \& Eizaguirre, C. 2016. Can environmental change affect host/parasite-mediated speciation? Zoology in press .

Buchmann, K. \& Kristensson, R.T. 2003. Efficacy of sodium percarbonate and formaldehyde bath treatments against gyrodactylus derjavini infestations of rainbow trout. N. Am. J. Aquac. 65: 25-27.

Buckling, A. \& Rainey, P.B. 2002. The role of parasites in sympatric and allopatric host diversification. Nature 420: 496-499.

Budria, A. \& Candolin, U. 2014. How does human-induced environmental change influence hostparasite interactions? Parasitology 141: 462-474.

Chellappa, S., Huntingford, F.A., Strang, R. \& Thomson, R.Y. 1995. Condition factor and hepatosomatic index as estimates of energy status in male three-spined stickleback. J. Fish Biol. 47: 775-787.

Cothran, R.D., Stiff, A.R., Jeyasingh, P.D. \& Relyea, R.A. 2012. Eutrophication and predation risk interact to affect sexual trait expression and mating success. Evolution 66: 708-719.

Domenici, P., Lefrancois, C. \& Shingles, A. 2007. Hypoxia and the antipredator behaviours of fishes. Philos. Trans. R. Soc. Lond. B Biol. Sci. 362: 2105-2121.

Eizaguirre, C. \& Lenz, T.L. 2010. Major histocompatibility complex polymorphism: dynamics and consequences of parasite-mediated local adaptation in fishes. J. Fish Biol. 77: 2023-2047.

Eizaguirre, C., Lenz, T.L., Kalbe, M. \& Milinski, M. 2012a. Rapid and adaptive evolution of MHC genes under parasite selection in experimental vertebrate populations. Nat. Commun. 3: 621.

Eizaguirre, C., Lenz, T.L., Kalbe, M., Milinski, M. \& Sorci, G. 2012b. Divergent selection on locally adapted major histocompatibility complex immune genes experimentally proven in the field. Ecol. Lett. 15: 723-731.

Eizaguirre, C., Lenz, T.L., Sommerfeld, R.D., Harrod, C., Kalbe, M. \& Milinski, M. 2011. Parasite diversity, patterns of MHC II variation and olfactory based mate choice in diverging three-spined stickleback ecotypes. Evol. Ecol. 25: 605-622.

This article is protected by copyright. All rights reserved. 
Eizaguirre, C., Lenz, T.L., Traulsen, A. \& Milinski, M. 2009a. Speciation accelerated and stabilized by pleiotropic major histocompatibility complex immunogenes. Ecol. Lett. 12: 5-12.

Eizaguirre, C., Yeates, S.E., Lenz, T.L., Kalbe, M. \& Milinski, M. 2009b. MHC-based mate choice combines good genes and maintenance of MHC polymorphism. Mol. Ecol. 18: 3316-3329.

Feulner, P.G.D., Chain, F.J.J., Panchal, M., Huang, Y., Eizaguirre, C., Kalbe, M., Lenz, T.L., Samonte, I.E., Stoll, M., Bornberg-Bauer, E. \& Others 2015. Genomics of divergence along a continuum of parapatric population differentiation. PLoS Genet. 11: e1004966.

Gilderhus, P.A. \& Marking, L.L. 1987. Comparative efficacy of 16 anesthetic chemicals on rainbow trout. N. Am. J. Fish. Manage. 7: 288-292.

Halstead, N.T., McMahon, T.A., Johnson, S.A., Raffel, T.R., Romansic, J.M., Crumrine, P.W. \& Rohr, J.R. 2014. Community ecology theory predicts the effects of agrochemical mixtures on aquatic biodiversity and ecosystem properties. Ecol. Lett. 17: 932-941.

Hamilton, W.D. \& Zuk, M. 1989. Parasites and sexual selection. Nature 341: 289-290.

Hammerschmidt, K. \& Kurtz, J. 2005. Evolutionary implications of the adaptation to different immune systems in a parasite with a complex life cycle. Proc. R. Soc. B. Sci. 272: 2511-2518.

Hayward, A.D., Nussey, D.H., Wilson, A.J., Berenos, C., Pilkington, J.G., Watt, K.A., Pemberton, J.M. \& Graham, A.L. 2014. Natural selection on individual variation in tolerance of gastrointestinal nematode infection. PLoS Biol. 12: e1001917.

Hendry, A.P., Bolnick, D.I., Berner, D. \& Peichel, C.L. 2009. Along the speciation continuum in sticklebacks. J. Fish Biol. 75: 2000-2036.

Howick, V.M. \& Lazzaro, B.P. 2014. Genotype and diet shape resistance and tolerance across distinct phases of bacterial infection. BMC Evol. Biol. 14: 56.

Huey, R.B., Pianka, E.R. \& Vitt, L.J. 2001. How often do lizards "run on empty"? Ecology 82: 1-7.

Jaervenpaeae, M. \& Lindstroem, K. 2004. Water turbidity by algal blooms causes mating system breakdown in a shallow-water fish, the sand goby pomatoschistus minutus. Proc. R. Soc. B. Sci. .

This article is protected by copyright. All rights reserved. 
Jakobsen, P.J., Johnsen, G.H. \& Larsson, P. 1988. Effects of predation risk and parasitism on the feeding ecology, habitat use, and abondance of lacustrine threespine stickleback (gasterosteus aculeatus). Can. J. Fish. Aquat. Sci. 45: 426-431.

Jochimsen, M.C., Kuemmerlin, R. \& Straile, D. 2013. Compensatory dynamics and the stability of phytoplankton biomass during four decades of eutrophication and oligotrophication. Ecol. Lett. 16: 81-89.

Johnson, P.T.J., Carpenter, S.R., Ostfeld, R., Keesing, F. \& Eviner, V. 2008. Influence of eutrophication on disease in aquatic ecosystems: patterns, processes, and predictions. In: Infectious disease ecology: effects of ecosystems on disease and of disease on ecosystems (R.S. Ostfeld, F. Keesing \& V.T. Eviner, eds), vol. 1, pp. 71-79. Princeton University Press.

Johnson, P.T.J., Chase, J.M., Dosch, K.L., Hartson, R.B., Gross, J.A., Larson, D.J., Sutherland, D.R. \& Carpenter, S.R. 2007. Aquatic eutrophication promotes pathogenic infection in amphibians. Proc. Natl. Acad. Sci. U.S.A. 104: 15781-15786.

Johnson, P.T.J., Rohr, J.R., Hoverman, J.T., Kellermanns, E., Bowerman, J. \& Lunde, K.B. 2012. Living fast and dying of infection: host life history drives interspecific variation in infection and disease risk. Ecol. Lett. 15: 235-242.

Johnson, P.T.J., Townsend, A.R., Cleveland, C.C., Glibert, P.M., Howarth, R.W., McKenzie, V.J., Rejmankova, E. \& Ward, M.H. 2010. Linking environmental nutrient enrichment and disease emergence in humans and wildlife. Ecol. Appl. 20: 16-29.

Kalbe, M., Wegner, K.M. \& Reusch, T.B.H. 2002. Dispersion patterns of parasites in 0+ year three-spined sticklebacks: a cross population comparison. J. Fish Biol. 60: 1529-1542.

Karvonen, A., Lucek, K., Marques, D.A. \& Seehausen, O. 2015. Divergent macroparasite infections in parapatric swiss lake-stream pairs of threespine stickleback (Gasterosteus aculeatus). PLoS One 10: e0130579.

Karvonen, A. \& Seehausen, O. 2012. The role of parasitism in adaptive Radiations-When might parasites promote and when might they constrain ecological speciation? Int. J.Ecol. 2012: 1-20.

This article is protected by copyright. All rights reserved. 
Kaufmann, J., Lenz, T.L., Milinski, M. \& Eizaguirre, C. 2014. Experimental parasite infection reveals costs and benefits of paternal effects. Ecol. Lett. 17: 1409-1417.

Kause, A. \& Ødegård, J. 2012. The genetic analysis of tolerance to infections: a review. Front. Genet. 3: 262.

Konijnendijk, N., Raeymaekers, J., Vandeuren, S., Jacquemin, L. \& Volckaert, F. 2013. Testing for local adaptation in the gasterosteus-gyrodactylus host-parasite system. Evol. Ecol. Res. 15: 489-502.

Kortet, R., Hedrick, A.V. \& Vainikka, A. 2010. Parasitism, predation and the evolution of animal personalities. Ecol. Lett. 13: 1449-1458.

Kurtz, J., Kalbe, M., Aeschlimann, P.B., Haeberli, M.A., Wegner, K.M., Reusch, T.B.H. \& Milinski, M. 2004. Major histocompatibility complex diversity influences parasite resistance and innate immunity in sticklebacks. Proc. R. Soc. B. Sci. 271: 197-204.

Leach, J.H., Johnson, M.G., Kelso, J.R.M., Hartmann, J., Nuemann, W. \& Entz, B. 1977. Responses of percid fishes and their habitats to eutrophication. J. Fish. Res. Board Can. 34: 1964-1971.

Lefèvre, T., Lebarbenchon, C., Gauthier-Clerc, M., Missé, D., Poulin, R. \& Thomas, F. 2009. The ecological significance of manipulative parasites. Trends Ecol. Evol. 24: 41-48.

Lucek, K., Roy, D., Bezault, E., Sivasundar, A. \& Seehausen, O. 2010. Hybridization between distant lineages increases adaptive variation during a biological invasion: stickleback in switzerland. Mol. Ecol. 19: 3995-4011.

Lucek, K., Sivasundar, A., Roy, D. \& Seehausen, O. 2013. Repeated and predictable patterns of ecotypic differentiation during a biological invasion: lake-stream divergence in parapatric swiss stickleback. J. Evo. Biol. 26: 2691-2709.

Lucek, K., Sivasundar, A., Seehausen, O. \& Carlson, S.M. 2012. Evidence of adaptive evolutionary divergence during biological invasion. PLoS One 7: e49377.

This article is protected by copyright. All rights reserved. 
Maan, M.E. \& Seehausen, O. 2011. Ecology, sexual selection and speciation. Ecol. Lett. 14: $591-602$.

MacColl, A.D.C. 2011. The ecological causes of evolution. Trends Ecol. Evol. 26: 514-522.

Magnusson, W.E., Lima, A.P., da Silva, W.A. \& de Araújo, M.C. 2003. Use of geometric forms to estimate volume of invertebrates in ecological studies of dietary overlap. Copeia 2003: 121129.

Marques, D.A., Lucek, K., Meier, J.I., Mwaiko, S., Wagner, C.E., Excoffier, L. \& Seehausen, O. 2016. Genomics of rapid incipient speciation in sympatric threespine stickleback. PLoS Genet. 12: e1005887.

Matthews, B., Harmon, L.J., M'Gonigle, L., Marchinko, K.B. \& Schaschl, H. 2010. Sympatric and allopatric divergence of MHC genes in threespine stickleback. PLoS One 5: e10948.

Milinski, M. 1993. Predation risk and feeding behaviour. In: Behaviour of teleost fishes (T. Pitcher, ed), vol. 1, pp. 285-305. Chapman \& Hall London.

Moser, D., Frey, A. \& Berner, D. 2015a. Fitness differences between parapatric lake and stream stickleback revealed by a field transplant. J. Evol. Biol .

Moser, D., Kueng, B. \& Berner, D. 2015b. Lake-stream divergence in stickleback life history: A plastic response to trophic niche differentiation? Evol. Biol. 42: 328-338.

Moser, D., Roesti, M. \& Berner, D. 2012. Repeated lake-stream divergence in stickleback life history within a central european lake basin. PLoS One 7: e50620.

Murray, D.L., Keith, L.B. \& Cary, J.R. 1998. Do parasitism and nutritional status interact to affect production in snowshoe hares? Ecology 79: 1209-1222.

Nosil, P. 2012. Ecological speciation. Oxford University Press, Oxford, UK.

Oke, K.B., Bukhari, M., Kaeuffer, R., Rolshausen, G., Raesaenen, K., Bolnick, D.I., Peichel, C.L. \& Hendry, A.P. 2016. Does plasticity enhance or dampen phenotypic parallelism? a test with three lake-stream stickleback pairs. J. Evol. Biol. 29: 126-143.

This article is protected by copyright. All rights reserved. 
Pianka, E.R. 1981. Resource acquisition and allocation among animals. Physiological ecology: an evolutionary approach to resource use. Blackwell Scientific Publishers, Oxford, UK pp. 300314.

Ponton, F., Lalubin, F., Fromont, C., Wilson, K., Behm, C. \& Simpson, S.J. 2011. Hosts use altered macronutrient intake to circumvent parasite-induced reduction in fecundity. Int. J. Parasitol. 41: $43-50$.

Poulin, R. 2007. Evolutionary ecology of parasites. Princeton University Press, Princeton, N.J.

R Core Team 2015. R: A Language and Environment for Statistical Computing. R Foundation for Statistical Computing, Vienna, Austria.

Råberg, L. 2014. How to live with the enemy: understanding tolerance to parasites. PLoS Biol. 12: e1001989.

Råberg, L., Graham, A.L. \& Read, A.F. 2009. Decomposing health: tolerance and resistance to parasites in animals. Philos. Trans. R. Soc. Lond. B Biol. Sci. 364: 37-49.

Raeymaekers, J.A.M., Wegner, K.M., Huyset, T. \& Volckaert, F.A.M. 2011. Infection dynamics of the monogenean parasite Gyrodactylus gasterostei on sympatric and allopatric populations of the three-spined stickleback Gasterosteus aculeatus. Folia Parasitol. 58: 27-34.

Rahn, A.K., Hammer, D.A. \& Bakker, T.C.M. 2015. Experimental infection with the directly transmitted parasite Gyrodactylus influences shoaling behaviour in sticklebacks. Anim. Behav. 107: 253-261.

Roesti, M., Kueng, B., Moser, D. \& Berner, D. 2015. The genomics of ecological vicariance in threespine stickleback fish. Nat. Commun. 6: 10229.

Schlotz, N., Ebert, D. \& Martin-Creuzburg, D. 2013. Dietary supply with polyunsaturated fatty acids and resulting maternal effects influence host-parasite interactions. BMC Ecol. 13: 41.

Schluter, D. 2000. The ecology of adaptive radiation. Oxford University Press, Oxford.

Schmid-Hempel, P. 2011. Evolutionary Parasitology: The Integrated Study of Infections, Immunology, Ecology, and Genetics. Oxford University Press, Oxford.

This article is protected by copyright. All rights reserved. 
Schneider, D.S. \& Ayres, J.S. 2008. Two ways to survive infection: what resistance and tolerance can teach us about treating infectious diseases. Nat. Rev. Immunol. 8: 889-895.

Seehausen, O., Butlin, R.K., Keller, I., Wagner, C.E., Boughman, J.W., Hohenlohe, P.A., Peichel, C.L., Saetre, G.P., Bank, C., Braennstroem \& Others 2014. Genomics and the origin of species. Nat. Rev. Genet. 15: 176-192.

Servedio, M.R., Doorn, G., Kopp, M., Frame, A.M. \& Nosil, P. 2011. Magic traits in speciation:'magic'but not rare? Trends Ecol. Evol. 26: 389-397.

Siva-Jothy, M.T. \& Thompson, J.J.W. 2002. Short-term nutrient deprivation affects immune function. Physiol. Entomol. 27: 206-212.

Smith, V.H. \& Schindler, D.W. 2009. Eutrophication science: where do we go from here? Trends Ecol. Evol. 24: 201-207.

Stephenson, J.F., Van Oosterhout, C., Mohammed, R.S. \& Cable, J. 2015. Parasites of trinidadian guppies: evidence for sex-and age-specific trait-mediated indirect effects of predators. Ecology 96: 489-498.

Streble, H. \& Krauter, D. 2006. Das leben im wassertropfen, 10. Auflage. Franckh-Kosmos .

Stutz, W.E., Lau, O.L. \& Bolnick, D.I. 2014. Contrasting patterns of phenotype-dependent parasitism within and among populations of treespine stickleback. Am. Nat. 183: 810-825.

Summers, K., McKEON, S.E.A., Sellars, J.O.N., Keusenkothen, M., Morris, J., Gloeckner, D., Pressley, C., Price, B. \& Snow, H. 2003. Parasitic exploitation as an engine of diversity. Biol. Rev. Camb. Philos. Soc. 78: 639-675.

Tachet, H., Richoux, P., Bournaud, M. \& Usseglio-Polatera, P. 2000. Invertébrés d'eau douce: systématique, biologie, écologie. CNRS éditions Paris.

Talbot, C. \& Hole, R. 1994. Fish diets and the control of eutrophication resulting from aquaculture. J. Appl. Ichthyol. 10: 258-270.

Van de Meutter, F., De Meester, L. \& Stoks, R. 2005. Water turbidity affects predator-prey interactions in a fish-damselfly system. Oecologia 144: 327-336.

This article is protected by copyright. All rights reserved. 
Vonlanthen, D., P.Bittner, Hudson, A.G., Young, K.A., Mueller, R., Lundsgaard-Hansen, B., Roy, D., Di Piazza, S., Largiader, C.R. \& Seehausen, O. 2012. Eutrophication causes speciation reversal in whitefish adaptive radiations. Nature 482: 357-362.

Wong, B.B.M. \& Candolin, U. 2015. Behavioral responses to changing environments. Behav. Ecol. 26: $665-673$.

Zuk, M. \& Stoehr, A.M. 2002. Immune defense and host life history. Am. Nat. 160: S9-S22.

Zuur, A., leno, E.N., Walker, N., Saveliev, A.A. \& Smith, G.M. 2009. Mixed effects models and extensions in ecology with $R$. Springer.

This article is protected by copyright. All rights reserved. 


\section{Acknowledgments}

We thank D. Steiner, D. Hohmann, C. Federer, M. Heckwolf, T. Ballesteros, S. Urbanski, A. Taverna and B. Kienholz for their assistance in the lab, in the mesocosm garden and in the field. We are very grateful for the support of the whole EAWAG Kastanienbaum community, especially to David Marquez, Kay Lucek and Tim Alexander for the kind introduction to the system and help with the statistics. We also like to thank Oliver Selz, Jessica Stephenson, and two anonymous reviewers for their useful comments on the manuscript and David Marquez and Julia Birtel for providing us with the pictures. This project was funded through the Lead Agency Project of the German Science Foundation (DFG, El841/4-1) and the Swiss National Science Foundation (SNSF 139326). The project was enabled by the stickleback cluster of the DFG priority program 1399 Host-Parasite Co-evolution and supported by a DFG grant to CE (EI 841/6-1).

This article is protected by copyright. All rights reserved. 


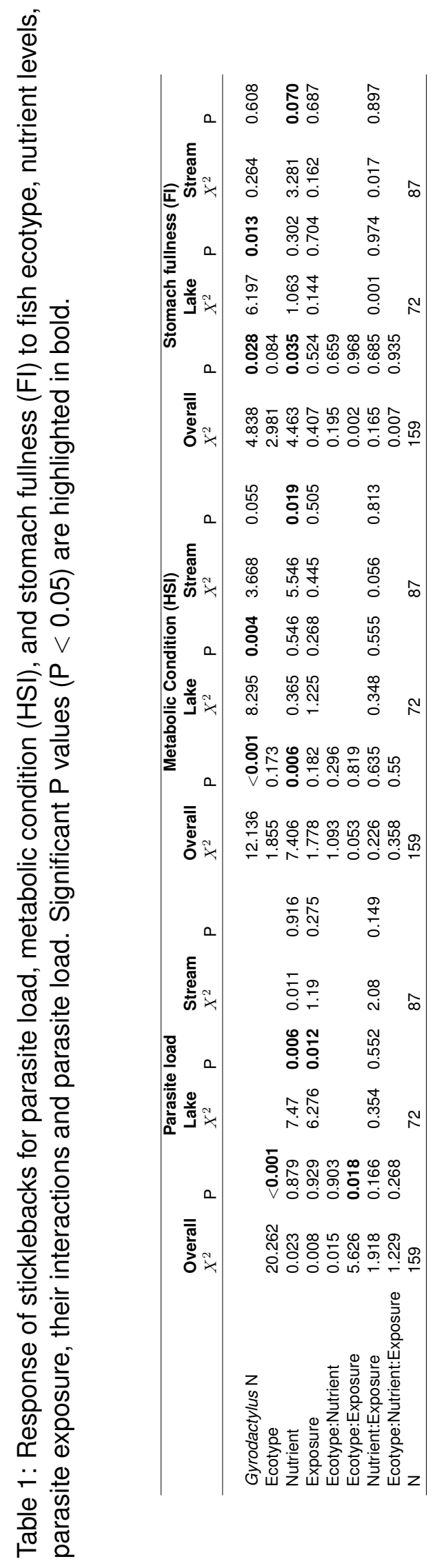

This article is protected by copyright. All rights reserved. 
Table 2: Effects on sticklebacks prey composition at the end of the experiment. $R^{2}$ values in the $\mathrm{db}-\mathrm{RDA}$ correspond to partial $R^{2}=$ explained sum of squares (SS) /Total SS Significant $\mathrm{P}$ values $(P<0.05)$ are highlighted in bold.

\begin{tabular}{|c|c|c|c|c|c|c|c|c|c|c|c|c|c|}
\hline & \multicolumn{13}{|c|}{ Prey composition (db-RDA) } \\
\hline & \multirow[b]{2}{*}{ DF } & \multicolumn{4}{|c|}{ Overall } & \multicolumn{4}{|c|}{$\begin{array}{l}\text { Lake } \\
\end{array}$} & \multicolumn{4}{|c|}{ Stream } \\
\hline & & SS & $\mathbf{F}$ & $\mathbf{P}$ & R2 & SS & $\mathbf{F}$ & $\mathbf{P}$ & R2 & SS & $\mathbf{F}$ & $\mathbf{P}$ & $\mathbf{R} 2$ \\
\hline Ecotype & 1 & 0.188 & 1 & 0.4 & 0.04 & & & & & & & & \\
\hline Nutrients & 1 & 0.283 & 1.508 & 0.181 & 0.06 & 0.311 & 1.285 & 0.277 & 0.143 & 0.171 & 1.227 & 0.31 & 0.102 \\
\hline Exposure & 1 & 0.464 & 2.469 & 0.045 & 0.099 & 0.307 & 1.272 & 0.302 & 0.141 & 0.219 & 1.574 & 0.202 & 0.131 \\
\hline Ecotype:Nutrients & 1 & 0.229 & 1.217 & 0.295 & 0.049 & & & & & & & & \\
\hline Ecotype:Exposure & 1 & 0.071 & 0.379 & 0.837 & 0.015 & & & & & & & & \\
\hline Nutrients:Exposure & 1 & 0.086 & 0.458 & 0.769 & 0.018 & 0.046 & 0.188 & 0.98 & 0.021 & 0.075 & 0.535 & 0.711 & 0.045 \\
\hline Ecotype:Nutrients:Exposure & 1 & 0.079 & 0.42 & 0.81 & 0.017 & & & & & & & & \\
\hline Total SS Sf $_{f}$ & & $4.7_{25}$ & & & & $2.176_{9}$ & & & & $1.671_{12}$ & & & \\
\hline
\end{tabular}

This article is protected by copyright. All rights reserved. 


\section{List of figures}

1. Experimental design. We crossed in a fully factorial design, lake and stream stickleback (A), exposure to Gyrodactylus (B), and nutrient loading in mesocosms environments (C).

2. Effects of the experimental treatments on $(A)$ the individual number of parasites, $(B)$ fish condition measured as the hepatosomatic index (HSI), (C) stomach fullness measured as the fullness index (FI), and (D) the relationship between HSI and FI. Symbols show mean values, shapes and colours represent ecotypes (circles = lake and squares $=$ stream) and Gyrodactylus exposure treatments (red $=\mathrm{G}+$ and blue $=\mathrm{G}-$ ). $\mathrm{X}$ axis show the nutrient effects $(\mathrm{HN}=$ high and $\mathrm{LN}=$ low). Bars in panels $A$ to $C$ represent $\pm S E)$.

3. Association between the number of parasites with fish condition (A-C), and stomach fullness (D-F). Panels A and D show the effects of parasite load on body condition (HIS) and relative stomach fullness (FI) for each ecotype. Panels B,C, E, and D show the effects of nutrient levels on the relationship between parasites and conditions on lake ( $A$ an $E)$ and stream ( $C$ and F) separately. Symbols' shapes and colours represent ecotypes (circles $=$ lake and squares $=$ stream) and nutrient treatments (dark green $=\mathrm{HN}$ and cyan $=L N)$. The lengths of the regression lines represent the rage of infection (resistance) and slope (tolerance) the degree of damage produced by increasing parasite infections. Slopes significantly different from 0 are marked with $\left({ }^{*}\right)$.

4. Effects on diet composition shown in a scaling 3 RDA biplot. Symbols' shapes and colours represent ecotypes $($ circles $=$ lake and squares $=$ stream $)$ and Gyrodactylus exposure treatments ( $r e d=G+$ and blue $=G-$ ). Arrows show the magnitude and direction of change of prey in the constrained multidimensional space (RDA axes). Centroids and bars represent the mean effect of the treatments and the standard errors. RDA explained variances are shown in brackets. ${ }^{*} P<0.05 ;{ }^{* *} P<0.01 ;{ }^{* * *} P<0.001$ show significant axes and significant effects on prey items (see supplementary material)

This article is protected by copyright. All rights reserved. 


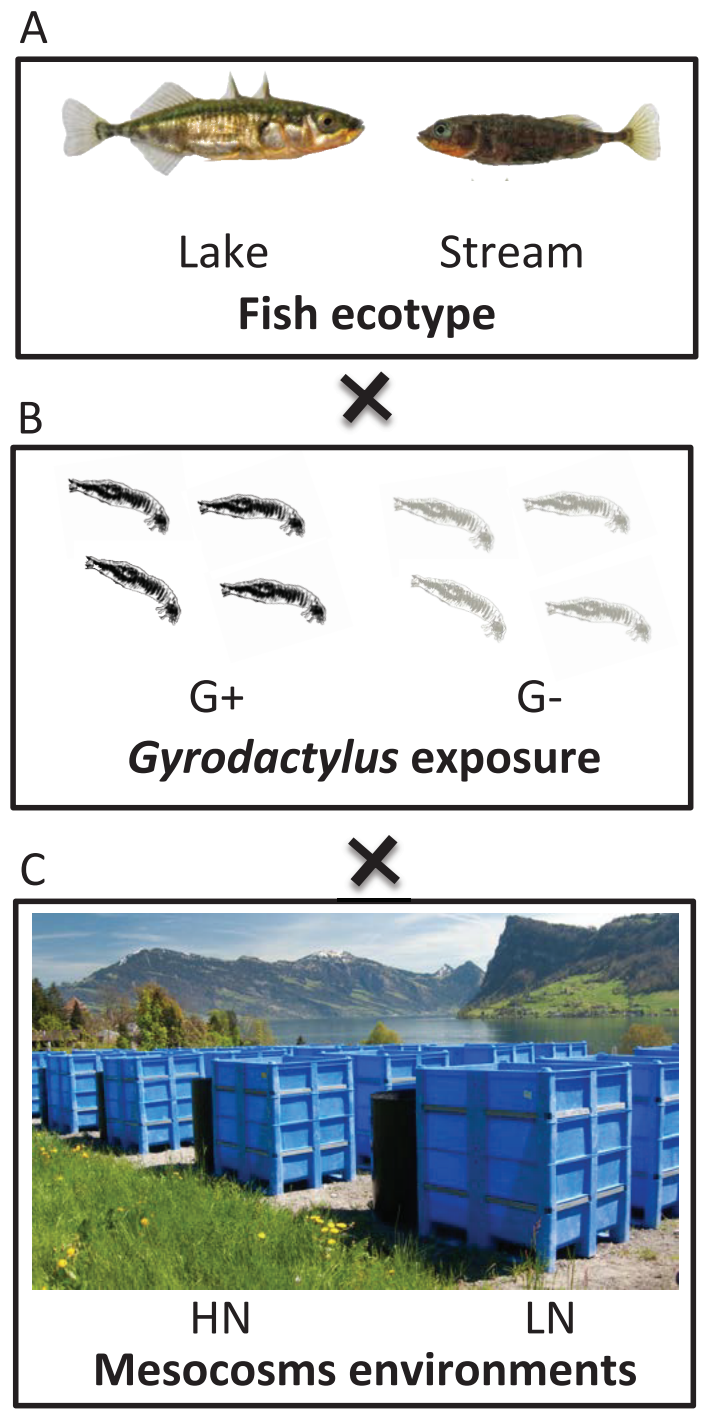

Figure 1:

This article is protected by copyright. All rights reserved. 
A
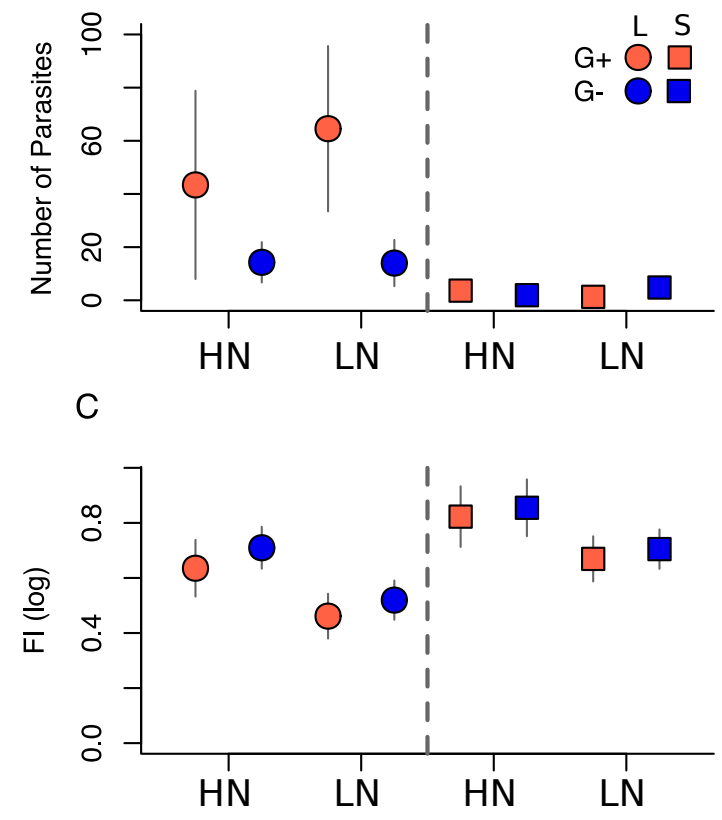

B
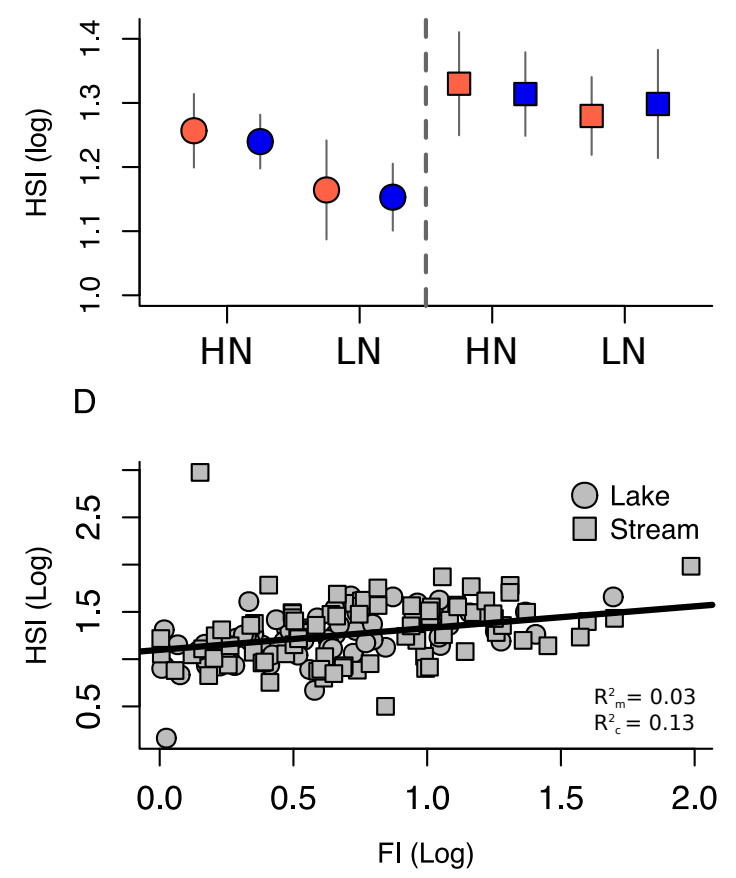

Figure 2:

This article is protected by copyright. All rights reserved. 
A

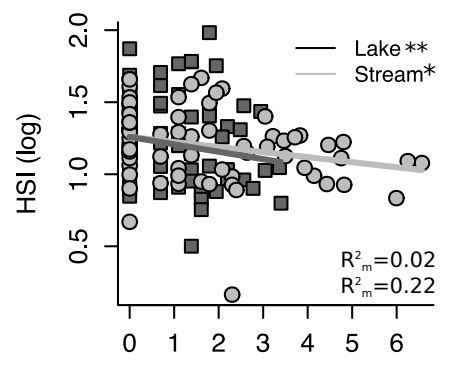

D

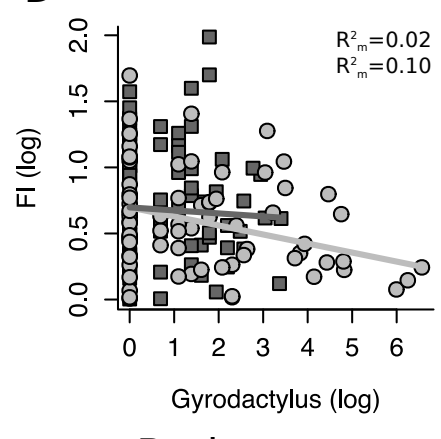

Both ecotypes
B

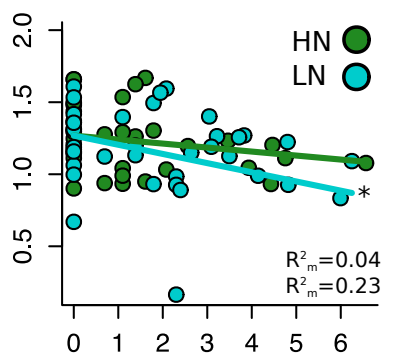

E

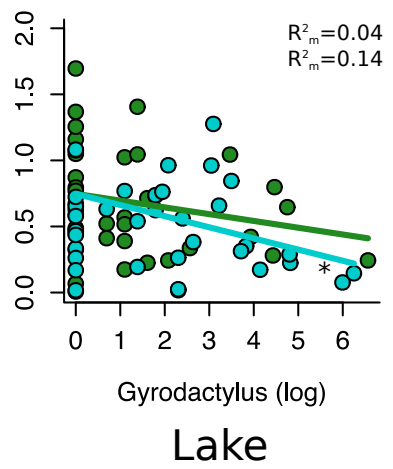

Lake
C

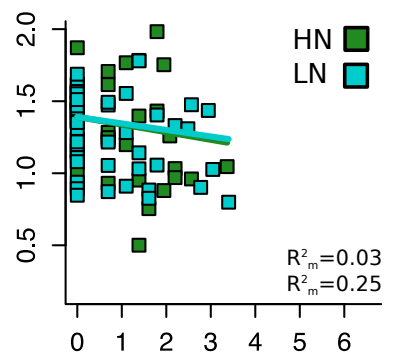

$\mathrm{F}$

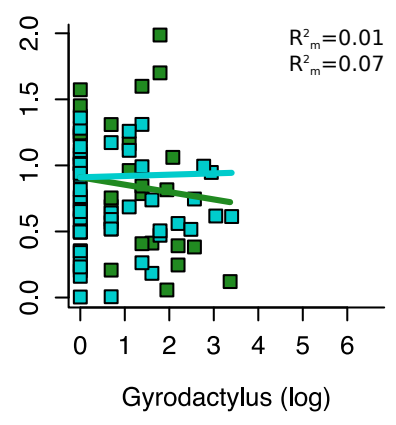

Stream

Figure 3:

This article is protected by copyright. All rights reserved. 


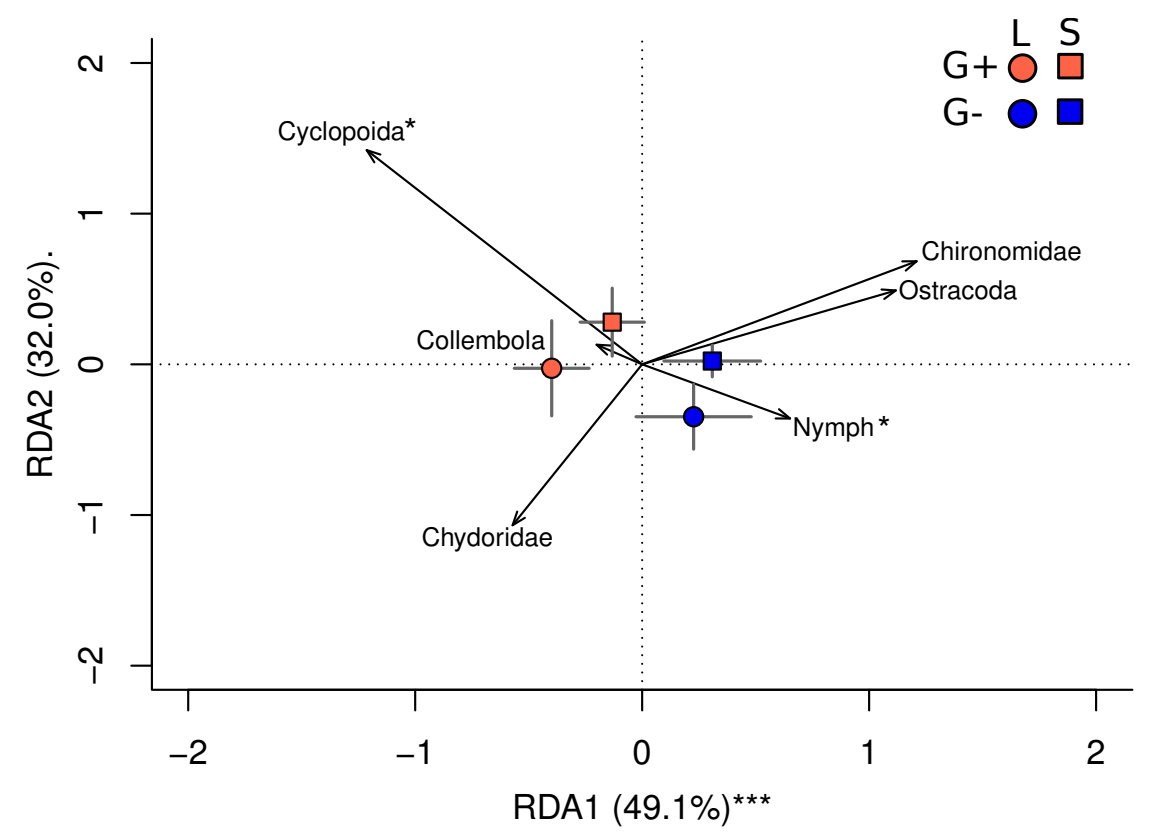

Figure 4:

This article is protected by copyright. All rights reserved. 